\title{
EL INFRUCTUOSO INTENTO DE REFORMA DE LA LEY DEL PATRIMONIO NATURAL Y BIODIVERSIDAD PRESENTADO PARAFAVORECER LAS ESPECIES INVASORAS
}

\author{
PEDRO BRUFAO CURIEL \\ Profesor Contratado Doctor \\ Universidad de Extremadura \\ pbrufao@unex.es
}

Recibido: 3 de julio de 2017 / Aceptado: 30 de octubre de 2017

RESUMEN: Este trabajo analiza la recientemente rechazada proposición de ley de reforma de la Ley del Patrimonio Natural y Biodiversidad, la principal norma española sobre Derecho de la Biodiversidad. El motivo de esta reforma se debe a una importante Sentencia del Tribunal Supremo de 2016 dictada sobre la clasificación y gestión de ciertas especies invasoras, que invalidó parcialmente una reforma del Catálogo Español de Especies Exóticas e Invasoras destinada a favorecer ciertas actividades relacionadas principalmente con la caza y la pesca. La conclusión principal de este estudio se basa en que ese intento de reforma ha sido un medio para eludir la aplicación de una sentencia del Tribunal Supremo, que conllevaría la vulneración del derecho fundamental a la tutela judicial efectiva, sin base científica alguna.

RESUM: Aquest treball analitza la recentment rebutjada proposició de llei de reforma de la Llei del patrimoni natural i de la biodiversitat, la principal norma espanyola sobre dret de la biodiversitat. Aquesta reforma es deu a una important sentència del Tribunal Suprem de 2016 dictada sobre la classificació i gestió de certes espècies invasores, que va invalidar parcialment una reforma del Catàleg espanyol d'espècies exòtiques $\mathrm{i}$ invasores destinada a afavorir certes activitats relacionades principalment amb la caça $\mathrm{i}$ la pesca. La conclusió principal d'aquest estudi és que aquest intent de reforma constitueix un mitjà per eludir l'aplicació d'una sentència del Tribunal Suprem que comportaria la vulneració del dret fonamental a la tutela judicial efectiva, sense cap base científica. 
ABSTRACT: This article treats the recently-rejected legislative bill to reform the Natural Heritage and Biodiversity Act, the main Spanish regulation on Biodiversity Law. The most likely reason to do so maybe to react against a Supreme Court case law that partly annulled a reform of the Exotic and Invasive Species Catalogue aiming at fostering some hunting and fishing interests. Our main conclusion drawn from this study is that the bill has tried to avoid the fulfillment of a Supreme Court sentence that would have led to the infringement, without scientific grounds, of the fundamental right to the effective judicial protection.

PALABRAS CLAVE: Ciencia y Derecho - Ley del Patrimonio Natural y Biodiversidad -Especies invasoras - Ejecución de sentencias.

PARAULES CLAU: Ciència i Dret - Llei del patrimoni natural i de la biodiversitat Espècies invasores - Execució de sentències.

KEY WORDS: Science and Law - Natural heritage and Biodiversity Law - Invasive species - Enforcement of judgments.

SUMARIO: I. Introducción. II. Sobre la exposición de motivos de la proposición de ley. III. La vuelta a un criterio rechazado por el Tribunal Supremo: los recursos zoogenéticos como concepto inválido para exceptuar el régimen aplicable a las especies invasoras. IV. La proposición de ley atacaba el mismo concepto y contenido del catálogo español de especies exóticas e invasoras. V. El ámbito temporal de la proposición de ley era el declarado nulo por el Tribunal Supremo. VI. El regreso sin amparo jurídico de las sueltas de ejemplares de trucha arcoíris (oncorhynchus mykiss) en el medio natural. VII. La proposición de ley incluía la renuncia ilegal a las competencias administrativas y la desconsideración de la validez de la prueba científica. VIII. La aplicación errónea por la proposición de ley del reglamento europeo de especies exóticas en la acuicultura. IX. Nota sobre la nueva proposición de ley presentada en octubre de 2017. X. Conclusiones. XI. Bibliografía.

\section{INTRODUCCIÓN}

Como es sabido, la Ley 42/2007, de 13 de diciembre, del Patrimonio Natural y Biodiversidad (LPNB) es la principal norma nacional que regula el llamado Derecho de la Biodiversidad ${ }^{1}$. Su contenido deriva principalmente del Derecho internacional y

\footnotetext{
${ }^{1}$ Sobre el Derecho de la Biodiversidad, vid. SORIANO GARCÍA, J. E. y BRUFAO CURIEL, P., Claves de Derecho Ambiental, Vol. II, Medio Natural biodiversidad y riesgos tecnológicos, Iustel, Madrid, 2011.
} 
europeo sobre la materia, que a su vez descansa en multitud de estudios científicos que muestran la estrecha ligazón existente entre Ciencia y Derecho ${ }^{2}$.

Sin embargo, a pesar de la certeza científica en la que basa este cuerpo legislativo, recientemente han surgido diferentes voces que solicitan la reforma de la LPNB con vistas a un aprovechamiento de especies animales y vegetales que contradicen sin base alguna los postulados científicos ${ }^{3}$.

A raíz de la Sentencia del Tribunal Supremo, Sala 3 $3^{\text {a }}$, de 16 de marzo de 2016, que anulaba en parte la reforma practicada por el RD 630/2013, de 2 de agosto, sobre el Catálogo Español de Especies Exóticas Invasoras (CEEI), se produjeron diversas manifestaciones que apuntaban, en la práctica, a dejar sin efecto la resolución del Alto Tribunal mediante la aprobación de una nueva norma reglamentaria que consiguiera eludir la inclusión de diversas especies en dicho CEEI. Sin embargo, esta propuesta fue olvidada y sustituida por una proposición de ley (PL) presentada en 2017 en el Congreso de los Diputados ${ }^{4}$, que al final fue rechazada el 20 de junio de este año ${ }^{5}$.

\footnotetext{
${ }^{2}$ El presente trabajo es la continuación de otros publicados en esta década, dado el iter legislativo y la actividad administrativa destinada, precisamente, a evitar la plena ejecución de sentencias firmes y al menos dificultar la adopción normativa de la evidencia científica: BRUFAO CURIEL, P., El Derecho y la Ciencia, o cómo desdeñar la sentencia del Tribunal Supremo sobre el catálogo de especies protegidas y negar la certeza científica, Revista Aranzadi Doctrinal, núm. 4, 2017. BRUFAO CURIEL, P., Las especies exóticas invasoras y el Derecho, con especial referencia a las especies acuáticas, la pesca recreativa y la acuicultura, Revista Catalana de Derecho Ambiental, vol. 3, núm. 1, 2012. En última instancia hablamos de la objetividad de los poderes públicos, la inconstitucionalidad de las normas publicadas para que las sentencias firmes no se ejecuten, la arbitrariedad de los actos que rechazan la certeza científica y la vulneración del derecho a la tutela judicial efectiva y la reserva de jurisdicción. Podemos afirmar sin ambages que esta materia es un ejemplo señero de la "captura del regulador". Asimismo, recomendamos la consulta de: COLLAZOS STÜWE, A., Comentarios al Decreto 213/2009, de 20 de noviembre, por el que se aprueban medidas para el control de especies invasoras en la Comunidad Valenciana, Revista Aranzadi de Derecho Ambiental, núm. 20, 2011. LOZANO CUTANDA, B., El Tribunal Supremo amplía el catálogo de especies invasoras (Sentencia de 16 de marzo de 2016), Actualidad Jurídica Ambiental, núm. 56, 2016.

${ }^{3}$ Como la votación en la Asamblea de la Región de Murcia el 20 de septiembre de 2017 de que el arruí o muflón del Atlas (Ammotragus lervia), pese a los estudios científicos que lo califican como especie invasora en toda España y así lo refleja el Dictamen del Comité Científico del Ministerio de Agricultura de 21 de marzo de 2017, en respuesta a la consulta CC 28/2017. Este mismo Comité califica la carpa (Cyprinus carpio) y sus variedades criadas como la "koi" como invasora en su Dictamen de 17 de noviembre de 2016 CC 25/2016.

${ }^{4}$ Boletín Oficial de las Cortes Generales (BOCG) de 9 de junio de 2017, Congreso de los Diputados, núm. 131-1, serie $B$.

${ }^{5}$ Boletín Oficial de las Cortes Generales (BOCG) de 26 de junio de 2017, Congreso de los Diputados, serie $\mathrm{B}$, núm. 131-2, Serie $\mathrm{B}$.
} 
No obstante, dado que a pesar de todo se sigue planteando en la actualidad la reforma de la $\mathrm{LPNB}^{6}$ con el fin de evitar los efectos de cosa juzgada de dicha STS, en este trabajo se analizan las causas de la presentación de esta PL y sus elementos básicos, en los que se mostrará que su fin ha sido, llanamente, un intento renovado de dejar sin efecto la sentencia del Tribunal Supremo, intento que ha desdeñado sin rubor la certeza científica probada en sede judicial y la amplia experiencia previa de las investigaciones científicas. Es más, el contenido de esta PL ha consistido en intentar dar validez a todo aquello declarado ilegal por el Alto Tribunal, un notorio ejemplo de "norma de convalidación". Para la mejor comprensión del objeto de este estudio aconsejamos la lectura previa de la sentencia, donde la prueba testifical, de índole científica, se convierte en la piedra clave del caso.

\section{SOBRE LA EXPOSICIÓN DE MOTIVOS DE LA PROPOSICIÓN DE LEY}

La exposición de motivos (EM) de la proposición de ley recoge la historia legislativa del Catálogo Español de Especies Exóticas Invasoras, aprobado como ya sabemos por el RD 630/2013, de 2 de agosto, para lo que emplea la "seguridad jurídica"7 como uno de los elementos clave de la reforma legislativa que se propone, cuando más bien debería hablarse de que el anterior RD de 2011 fue objeto de derogación debido a la resistencia a su aplicación por diversos sectores, más que de "problemas de aplicación".

A continuación se refiere a la STS, Sala $3^{\mathrm{a}}$, Sección $5^{\mathrm{a}}, \mathrm{n}^{\mathrm{o}} 637 / 2016$, de 16 de marzo ${ }^{8}$, sobre la cual explica la EM que ha causado una gran preocupación por ciertos efectos económicos y sociales, añadiendo que implicaba la prohibición genérica de posesión, transporte, tráfico y comercio de ejemplares vivos de varias especies que son objeto de aprovechamiento piscícola o cinegético, lo cual ha supuesto la imposibilidad de la práctica de caza y pesca deportivas de las especies catalogadas, salvo en el marco de campañas de control y erradicación, así como ciertas actividades económicas

\footnotetext{
${ }^{6}$ Con la oposición de entidades ambientales. Vid. nota de prensa conjunta de 11 de julio de 2017 de SEO/Birdlife, WWF-España, Ríos con Vida y Ecologistas en Acción: "Las organizaciones ecologistas se oponen a un nuevo intento de modificación de la Ley de Patrimonio Natural y Biodiversidad". Ese día se presentó su documento: "Especies exóticas e invasoras. 25 preguntas y respuestas", disponible en la página web de cada una de estas entidades.

${ }^{7}$ Esta invocación a la seguridad jurídica ha sido una de las llamadas más recurrentes tras el dictado de la STS sobre el CEEI, algo que desdeña el hecho de que es precisamente una sentencia firme la que otorga tal seguridad jurídica, máxime si se trata de anular disposiciones normativas. Otras expresiones semejantes hacen referencia a la "preocupación"

${ }^{8}$ Hay una errata, pues el BOCG recoge que fue dictada el 2 de agosto de 2016.
} 
industriales como la del cangrejo rojo (Procambarus clarkii) o la trucha arcoíris (Oncorhynchus mykiss).

En primer lugar, hemos de decir, en contra de lo expresado en múltiples ocasiones, que ni la caza ni la pesca recreativas de estas especies se han visto prohibidas, sino que simplemente se pueden emplear como método de control y erradicación (art. 10.5 del CEEI), cuyo impacto económico y social se ha alegado pero del que no hemos encontrado nada por parte de los defensores de ciertos aprovechamientos y fomento de algunas especies invasoras que aporten datos contrastados en el tiempo transcurrido desde que se dictó la STS $^{9}$. También incurre en el error de que el CEEI y la STS afectan a la cría de animales de producción de especies como la trucha arcoíris, porque únicamente se prohíbe la suelta en el medio natural (art. 7.2 del CEEI). De hecho, la producción comercial destinada a la alimentación humana no se ha visto afectada.

Por tanto, no guarda lógica alguna el que la EM adujera que era preciso encontrar una "solución" que compatibilizase la protección del medio ambiente de conformidad con la Sentencia del Tribunal Supremo. Decimos que no guarda lógica alguna cuando es una sentencia firme, y mucho más dictada por el Alto Tribunal, la que establece el marco jurídico oportuno y su correcta interpretación, siendo una sentencia firme la que guarda la última palabra en un Estado de Derecho sobre una cuestión determinada, por lo que

\footnotetext{
${ }^{9}$ Generalmente se han dado cifras de 3.000 millones de euros y 10.000 puestos de trabajo, cifras demasiado redondas y sin cita de trabajo o estudio alguno. Vid. "ABC" de 5 de junio de 2016 o "El Confidencial" de 8 de junio de 2016, datos que se ofrecieron a los pocos meses de dictarse la sentencia. Esas cifras resultan en $300.000 € /$ año/trabajador y suponen unos $157 € /$ hora trabajada, rentabilidad y opulencia que no explican una huida masiva de otros empresarios y empleados a este sector. Además, la pesca de invasoras se centra en especies como el siluro, el lucioperca o la perca americana, especies que llevan incluidas desde sus orígenes en el catálogo de especies invasoras, sin que veamos tal destrucción de puestos de trabajo ni la hecatombe del sector. Estas citas sin fundamento alguno se han dado en los medios de comunicación en relación con las diversas reuniones mantenidas con la Ministra de Agricultura y la Secretaria de Estado de Medio Ambiente por parte de interesados en la pesca de especies invasoras. Nadie puede dar crédito a estas cifras de la pesca recreativa de agua dulce cuando las comparamos, por ejemplo, con la totalidad del sector minero: "En 2013 la contribución del sector minero en España, en términos de empleo directo, en las 2.942 explotaciones, fue de 29.705 empleos, de los cuales 21.605 correspondieron a la extracción de minerales no metálicos (industriales, ornamentales, productos de cantera), 4.489 a minerales energéticos y 3.611 a minerales metálicos. Según la última estadística minera de 2013, el valor de la producción vendible para el conjunto del sector minero fue de $3.254 \mathrm{M} €$, prácticamente igual al de $2012(0,3 \%) "$. Texto tomado del portal oficial del Ministerio de Industria, Energía y Turismo: http://www.minetur.gob.es/energia/mineria/Paginas/Index.aspx
}

En resumen, el respeto institucional y el cumplimiento del deber de servir con objetividad los intereses generales exige que se tengan en cuenta datos veraces, reales y contratados, cumpliendo en sus estrictos términos las resoluciones judiciales. Sobre estos datos a raíz de la STS se ha hecho eco el editorial de la revista "Quercus" del no 365, de julio de 2016. Por el contrario, los efectos económicos y sociales de las EEI son muy conocidos, del orden de 12.000 millones de euros al año en la UE. Vid. UNIÓN EUROPEA, Especies exóticas invasoras. La respuesta de la Unión Europea, Luxemburgo, 2014. pág. 11. 
carece de sentido el que se trate de "encontrar una solución", a pesar de que se recalque el cumplimiento de la STS, pues la solución en un Estado de Derecho solo la dan los jueces y tribunales y la doctrina de la cosa juzgada material ${ }^{10}$.

A continuación, la EM se refiere a la definición de "recurso zoogenético", otra de las cuestiones jurídicas que motivaron la nulidad de lo dispuesto en el CEEI, y a pesar de lo que se pretende reformar ya se recoge en la LPNB y el CEEI en cuanto al empleo de la caza y la pesca como instrumentos de control y erradicación, por lo que resulta asimismo ilógico el que se incluyese en esta PL, máxime cuando cita la "información científica", siendo que los estudios que avalan el carácter invasor de una especie ya confirman sin duda alguna tal carácter sobre las especies objeto de la reforma, como el cangrejo rojo o la trucha arcoíris.

Asimismo, la EM recoge otra cuestión declarada ilegal por el TS acerca de la pesca recreativa intensiva de la trucha arcoíris, que implica de suyo la suelta en el medio natural, ya que dice que para disminuir la presión de pesca sobre los tramos con trucha autóctona, se permitiría la suelta de truchas arcoíris en tramos concretos y con ejemplares sin ninguna capacidad reproductiva. Este punto se analizará más abajo, pero sorprende el que se liguen dos especies diferentes de trucha cuando los efectos ambientales superan con mucho a una determinada especie.

Para terminar con este apartado, la EM ampara una excepción al régimen general de las especies invasoras que de hecho lo convierte en inútil, ya que con un lenguaje propio de la Directiva de Hábitats de la UE, dice que se habilita un "mecanismo excepcional para que la Comisión Estatal de Patrimonio Natural y la Biodiversidad pueda acordar, en casos excepcionales, cuando exista un interés público de primer orden y siempre que existan las garantías necesarias de que no se producirán efectos negativos sobre la biodiversidad autóctona, el levantamiento de algunas de las prohibiciones genéricas que se aplican a las especies catalogadas".

\footnotetext{
${ }^{10}$ Causa asombro, por tanto, que se lean declaraciones como esta:"El Gobierno regional prorrogará la orden de veda vigente y, de esta forma, se evitará ejecutar la decisión del Supremo", Diario Hoy de Extremadura, de 19 de septiembre de 2017: "La Junta prorroga la orden de veda para que las carpas pescadas vuelvan al agua".
} 
III. LA VUELTA A UN CRITERIO RECHAZADO POR EL TRIBUNAL SUPREMO: LOS RECURSOS ZOOGENÉTICOS COMO CONCEPTO INVÁLIDO PARA EXCEPTUAR EL RÉGIMEN APLICABLE A LAS ESPECIES INVASORAS

La PL incluyó una referencia al concepto de "recursos zoogenéticos" que ya fue rechazada de plano por el Tribunal Supremo al analizar la cuestión de las poblaciones de cangrejo rojo americano en el medio natural

Como hemos advertido más arriba, la reforma de este concepto científico es sin duda alguna la respuesta a la anulación por el TS, gracias al subterfugio, ya declarado nulo por el TS, de referirse a la pesca en el medio natural del cangrejo rojo americano, siendo que los recursos zoogenéticos se refieren a los reproductores que se emplean como medio de mejora de razas y especies ganaderas, regulados por el Derecho Alimentario ${ }^{11}$, pero no mediante su captura en el medio natural como es el caso de este crustáceo ${ }^{12}$. Es decir, el motivo real de la reforma de la LPNB sobre este aspecto es claramente evitar lo dispuesto por el Alto Tribunal, como patente ejemplo de reforma legal destinada a ser sin más una norma de convalidación. Esta misma cuestión ha sido ya recurrida ante los tribunales contencioso-administrativos al respecto de una Orden de la Junta de Andalucía que elude sin motivación jurídica la aplicación de los medios de erradicación y control efectivo de esta especie en las marismas del Guadalquivir.

A su vez y por lo que respecta al visón americano (Neovison vison) y su posible consideración como "recurso zoogenético", recordamos que esta especie es una de las

\footnotetext{
${ }^{11}$ Disposición adicional tercera de la LPNB. Como ejemplo del carácter eminentemente ganadero o de la acuicultura, pero no la captura en el medio natural de cangrejos silvestres con nasas y redes, la cual nada tiene que ver con la conservación y mejora de razas o el establecimiento de bancos de germoplasma. Vid. la Comisión de Recursos Genéticos para la Alimentación y la Agricultura de la FAO: http://www.fao.org/nr/cgrfa/cgrfa-home/es/

${ }^{12}$ El Tribunal Supremo anuló también otra de las excepciones al régimen general aprobada por el CEEI de 2013, en esta ocasión bajo el concepto de los "recursos zoogenéticos" en relación con el cangrejo rojo americano $^{12}$, ya que su comercialización "no guardan relación alguna" con su finalidad zoogenética, objeto esta de límites intrínsecos de carácter científico y técnico, pues esta especie no encuentra cobijo bajo la normativa aplicable de pesca marítima, al ser una especie continental. El TS señala que el RD de 2013 se contradice al calificar el cangrejo rojo como especie invasora, una de las más dañinas a escala mundial, y a continuación esta norma anula el régimen general al exceptuarlo en cuanto a su comercialización, pues, añade el TS, no se pueden asimilar la alimentación humana de una especie con un recurso zoogenético. En efecto, los recursos genéticos son la información o material genéticos empleados para la conservación, fomento o mejora de las razas gracias a la selección de los mejores ejemplares y su material reproductivo, pero no el que los ejemplares de una especie se capturen con destino a la industria agroalimentaria, burdo subterfugio empleado por la Administración que el TS declara contrario a Derecho al quedar muy lejos de las excepciones permitidas, que como sabemos ya se refieren a la investigación, la salud y la seguridad de las personas". Vid. BRUFAO CURIEL, P. (2017), op. cit.
} 
invasoras más dañinas que se encuentran en España y la UE, por sus efectos sobre todo en el ecosistema fluvial y sobre mamíferos ligados a los ríos tan amenazados como el visón europeo (Mustela lutreola), especie que se encuentra en España en una situación peor que la del lince ibérico y que es objeto de diversos proyectos LIFE.

La apertura de nuevas granjas no puede considerarse como un recurso zoogenético, sino solamente el que algunos ejemplares y sus bancos de germoplasma se empleen en la mejora ganadera de sus explotaciones. A ello se le suma la ratio decidendi de la STS, que anula la Disposición adicional sexta del RD de 2013, la cual excluía nuevas granjas de esta "especie sumamente dañina" (sic) solo en los lugares donde todavía existe el visón autóctono europeo, porque (FJ 6) considera esta medida "inconciliable" con la prohibición genérica del empleo de especies invasorasdel art. 61.3 de la LPNB, que no admite excepciones o salvedades genéricas, salvo razones imperiosas de protección de la investigación, la salud o la seguridad de las personas que aquí no sólo no concurrían, afirma el TS, sino que la regulación reglamentaria prescindía de ellas, pues sólo permiten las excepciones singulares basadas en criterios relativos a la investigación, la salud o la seguridad de las personas.

Reincidir en una cuestión anulada por el TS resulta, por tanto, del todo impropia en una proposición de ley, una vez más como ejemplo preclaro de norma de convalidación y de vulneración del derecho fundamental a la tutela judicial efectiva.

\section{LA PROPOSICIÓN DE LEY ATACABAEL MISMO CONCEPTO Y CONTENIDO DEL CATÁLOGO ESPAÑOL DE ESPECIES EXÓTICAS E INVASORAS}

La PL pretendía reformar el art 64 de la LPNB, que regula el CEEI. Para ello repite lo regulado en la actualidad, pero en el segundo párrafo del art. 64.3 propuesto establecía excepciones a la prohibición general del empleo de especies invasoras "por otros motivos imperiosos de interés público incluidos los de naturaleza social o económica", para lo cual la Comisión Estatal para el Patrimonio Natural y de la Biodiversidad podría dejar sin efecto, mediante acuerdo, algunas prohibiciones para una determinada especie catalogada, incorporando ciertas garantías para asegurar efectos negativos sobre la biodiversidad autóctona.

La alusión a "motivos imperiosos de interés público", como hemos adelantando más arriba, deriva del art. 6.4 de la Directiva de 92/43/CE, de Hábitats, y de la excepción al 
régimen general de protección de los hábitats y especies recogidos en los anexos de esta norma europea, ampliamente tratados por la jurisprudencia del Tribunal Europeo de Justicia $^{13}$, que implica la evaluación de los efectos de proyectos en la Red Natura 2000, la existencia de alternativas y la aplicación de medidas compensatorias.

Es evidente, sin embargo, que recurrir a la jerga y conceptos jurídicos de nada menos que la Directiva de Hábitats no casa en modo alguno con lo que se pretendía con la PL, que era, sin más, aprobar una norma de convalidación que atentaría contra el derecho fundamental a la tutela judicial efectiva lograda en este caso ante el TS. En cuanto a los motivos socioeconómicos, dado que no se han aportado estudios científicos que lo avalen, vemos que caen por su misma base, ya que el carácter "imperioso" ${ }^{14}$ se ha interpretado por el TJUE bajo el criterio restrictivo de la garantía máxima de las obligaciones de conservación de la Directiva de Hábitats, tal y como lo demuestra la STJUE de 24 de noviembre de 2011, C-404/2009, Comisión/España, apartados 153 a 159 y 192 a 195: "Los incumplimientos que se han constatado del artículo 6, apartado 2, de la Directiva sobre los Hábitats no pueden justificarse por la importancia de las actividades mineras para la economía local".

Si este caso se refería a las canteras a cielo abierto de la cuenca del Sil y del empleo en una zona rural marginada ${ }^{15}$, mucho más se puede inferir de conjeturas que chocan frontalmente con la evidencia científica. Y la referencia a la adopción de medidas para evitar la afección negativa de estas autorizaciones excepcionales, cuando la mera presencia de estas especies invasoras es la que conlleva el daño ambiental, es lo que convierte a esta previsión en un concepto vacío y, por tanto, arbitrario, una mera referencia sin contenido normativo alguno propio de la peor técnica de redacción legislativa, ya que no se puede establecer una cosa y su contraria, máxime cuando no hay duda científica al respecto ${ }^{16}$.

\footnotetext{
${ }^{13}$ Este art. 6. 4 dice así: "Si, a pesar de las conclusiones negativas de la evaluación de las repercusiones sobre el lugar y a falta de soluciones alternativas, debiera realizarse un plan o proyecto por razones imperiosas de interés público de primer orden, incluidas razones de índole social o económica, el Estado miembro tomará cuantas medidas compensatorias sean necesarias para garantizar que la coherencia global de Natura 2000 quede protegida. Dicho Estado miembro informará a la Comisión de las medidas compensatorias que haya adoptado".

${ }^{14}$ Diccionario de la RAE: "Imperioso. 3. Que conlleva fuerza o exigencia".

${ }^{15}$ Vid. en el mismo sentido la STJUE de 3 de abril de 2014, C-30172012, Cascina Tre Pini, apartado 34, en relación con la evaluación ambiental previa del proyecto del art. 6.3 de la Directiva de Hábitats

${ }^{16}$ Un ejemplo, aparte de la abundante bibliografía científica al respecto: "Ignacio Doadrio, investigador del CSIC, coordinador del libro rojo mencionado y experto en peces continentales, asegura que "no existe un solo científico que firme un estudio que diga que las sueltas de trucha arco iris no influyen en el
} 
El FJ 5 de la STS, a propósito del arruí y su exclusión como especie invasora en Murcia, que anula, dice de este carácter "imperioso":

"Tal excepcional caso no es aquí concurrente, pues se exigiría una autorización administrativa singular -en presencia de poderosas y probadas razones concurrentesque, además, no podrían ser cualesquiera, sino sólo las encaminadas a la investigación, salud o seguridad de las personas, que no es el caso en que se sustenta".

Por otra parte, la LPNB, en consonancia con la Directiva de Hábitats, regula tal carácter imperioso, cuya declaración compete a una ley o al Consejo de Ministros (art. 46 de la LPNB) y no al Consejo Estatal para el Patrimonio Natural y de la Biodiversidad, pero siempre que haya una evaluación previa rigurosa, que sus resultados hayan sido ambientalmente negativos y que se establezcan medidas compensatorias si afectan a la Directiva de Hábitats, relacionados con la salud y la seguridad de las personas. Nada de esto aparece en la PL.

En cuanto al capítulo en que se incluye el CEEI (art. 61 de la LPNB sobre las excepciones a las prohibiciones del Capítulo I- Conservación in situ de la biodiversidad autóctona silvestre- del Título III de la LPNB -Conservación de la biodiversidad- de la LPNB), su interpretación sistemática nos conduce exclusivamente a que el bien jurídico protegido es la biodiversidad autóctona silvestre y que corresponde la carga de la prueba en sentido contrario el tomar alguna medida a favor de las especies alóctonas e invasoras, tarea harto difícil por no decir imposible cuando la abrumadora prueba científica señala justo lo contrario de lo que esta reforma pretende.

Tal excepción, en la práctica, supondría su conversión en un medio para favorecer la presencia de las especies invasoras, o lo que es lo mismo, supondría el vaciamiento de contenido de la conservación de la biodiversidad autóctona, claro ejemplo de ley ad casum o de caso único incompatible con el carácter general de las leyes, que además vulneraría el efecto de cosa juzgada material de la STS.

Sorprende además, en cuanto a la técnica legislativa empleada que se proponga la reforma de una parte muy concreta del art. 64 de la LPNB, pero se incluya repetido el artículo entero en la PL, lo que para algún lector puede llevar a confusión, suponemos que debido simplemente a una mera incorrecta técnica legislativa.

ecosistema y que la especie no compite y desplaza a otros peces en su alimentación". El País, de 17 de abril de 2010. 


\section{EL ÁMBITO TEMPORAL DE LA PROPOSICIÓN DE LEY ERA EL DECLARADO NULO POR EL TRIBUNAL SUPREMO}

El art. 64 ter de la PL es un ejemplo patente del empleo inconstitucional de las normas de convalidación cuyo fin exclusivo era, como hemos visto ya en varias ocasiones, evitar la acción de la justicia y la llamada "reserva de jurisdicción", es decir, que mediante una ley se aparte el espacio propio de los jueces y tribunales ${ }^{17}$, afectando además al derecho fundamental a la tutela judicial efectiva y a la posibilidad de recurrir a la jurisdicción ordinaria, pues se eleva una cuestión reglamentaria a rango formal de ley, dejándose apenas de este modo la ardua vía del recurso de amparo o recurso de inconstitucionalidad.

El verano de 2016 se expuso en información pública un borrador de Real Decreto de reforma del CEEI, con vistas a "dar soluciones" a la STS, norma reglamentaria de la que nada se ha sabido después, a la vez que se han sucedido los contactos en el Ministerio de Agricultura en este mismo sentido, cuando en 2017 se presenta esta PL, con el patente resultado de reducir las posibilidades de recurso.

En efecto, el art. 64 ter de la PL dice en sus tres primeros párrafos prácticamente lo mismo que lo declarado ilegal por el Tribunal Supremo ${ }^{18}$.

\footnotetext{
${ }^{17}$ BRUFAO CURIEL, P., Normas de convalidación de actos y disposiciones administrativas anuladas en sede contenciosa, en Bauzá Martorell, F. J. (dir.): Derecho Administrativo y Derecho Penal: Reconstrucción de los límites, Bosch, Barcelona, 2017.

18 "Artículo 64 ter. Especies catalogadas como exóticas invasoras introducidas en el medio natural con anterioridad a la entrada en vigor de la Ley 42/2007, de 13 de diciembre, objeto de aprovechamiento piscícola o cinegético. Sueltas con la especie trucha arco iris. 1. Para evitar que las especies catalogadas objeto de aprovechamiento piscícola o cinegético, introducidas en el medio natural antes de la entrada en vigor de la Ley 42/2007, de 13 de diciembre, se extiendan fuera de los límites de sus áreas de distribución anteriores a esa fecha, su gestión, control o posible erradicación se podrá realizar, en esas áreas, a través de la caza y la pesca, incluyendo todas sus modalidades, incluidas las reguladas por las Federaciones Deportivas Españolas de Caza y de Pesca, cuando este objetivo quede recogido en los instrumentos normativo de caza y pesca. 2. Las comunidades autónomas y ciudades de Ceuta y Melilla podrán utilizar los instrumentos de planificación y gestión en materia de caza y pesca para determinar las especies que, en su ámbito territorial, se ven afectadas por el contenido del apartado anterior. La posibilidad de caza y pesca quedará supeditada a la aprobación, previa a la aprobación de los primeros instrumentos de planificación y gestión en materia de caza y pesca, de la delimitación cartográfica del área ocupada por dichas especies antes de la fecha de aprobación de la Ley 42/2007, realizada por la administración competente de la comunidad autónoma y tras su publicación en el Boletín Oficial de la comunidad autónoma. Esta delimitación deberá basarse en la información disponible en cada comunidad autónoma, o en su defecto en la que figura en el Inventario Español del Patrimonio Natural y la Biodiversidad proporcionada de forma oficial por las comunidades autónomas y ciudades de Ceuta y Melilla, en aplicación del apartado 1 del artículo 12 del Real Decreto 556/2011, de 20 de abril. 3. Cuando se detecte la presencia de ejemplares de especies catalogadas objeto de aprovechamiento piscícola o cinegético fuera de las áreas de distribución contempladas en el apartado 2, no se podrá autorizar en esas zonas su caza o pesca. En este caso, las Administraciones competentes deberán proceder, en la medida de sus posibilidades, al control y posible erradicación de estas especies mediante metodologías apropiadas".
} 
Asombra y deja perplejo esta tosca reforma cuando se trata precisamente de la declarada por el TS nula de pleno Derecho Disposición transitoria segunda del RD de CEEI de 2013, dado que a pesar de ese pretendido carácter transitorio, tiene un contenido permanente. La añagaza de acudir a su elevación de rango, yendo derechamente contra una sentencia del Tribunal Supremo, no puede hacernos olvidar además que va contra el mero concepto de lo que puede ser una norma transitoria.

La STS lo afirma así en el FJ 8, cuando afirma que no cabe olvidar que estamos en presencia de especies sumamente agresivas para otras especies autóctonas y, en general, para los ecosistemas y hábitats, pues tal es un hecho probado y que el estatuto de protección y salvaguarda que brinda la incorporación al Catálogo no puede hacerse depender de un dato superfluo desde el punto de vista de la información científica en este campo de la biodiversidad y sus amenazas, como es el momento de introducción de la especie, "pues las catalogadas lo son, lo deben ser, al margen de la antigüedad de su presencia en las aguas continentales, a menos que se hubiera acreditado que el elemento cronológico resulta relevante a efectos de la procedencia de la catalogación de la especie".

El TS argumenta al respecto que se trata de una disposición transitoria que no es, en rigor, transitoria, sino que provee un régimen prolongado de disfrute de determinadas situaciones, por tiempo indefinido, en favor de actividades cinegéticas o piscícolas legítimas a priori, "pero que no pueden prevalecer frente a los valores superiores que se tratan de preservar con el Catálogo de previsión legal, de suerte que será legal, incluso encomiable y susceptible de protección la caza y la pesca, cuando no se haga objeto de ellas especies catalogadas, que lo son por sus perniciosos efectos sobre el medio ambiente y, en especial, sobre las especies autóctonas y los hábitats y ecosistemas".

\section{EL REGRESO SIN AMPARO JURÍDICO DE LAS SUELTAS DE EJEMPLARES DE TRUCHA ARCOÍRIS (Oncorhynchus mykiss) EN EL MEDIO NATURAL}

El párrafo cuarto del nuevo art. 64. ter de la PL añadía que con el fin de restar presión de pesca a las poblaciones de la especie trucha común (Salmo trutta), las comunidades autónomas podrían permitir, previa autorización administrativa, las sueltas de trucha 
arcoíis (Oncorhynchus mykiss) ${ }^{19}$ exclusivamente en las masas de agua en las que estas sueltas se hubieran autorizado antes de la entrada en vigor de la LPNB y con ejemplares criados en cautividad, procedentes de cultivos monosexo y sometidos a tratamiento de esterilidad.

La reforma propuesta representaba un ataque directo al fallo de la sentencia, que declaró nula en su fallo la exclusión de esta especie del CEEI:

" (...) debemos declarar y declaramos la nulidad de éste, por ser disconforme con el ordenamiento jurídico, exclusivamente en lo que se refiere a los siguientes extremos, con desestimación de los restantes pretensiones ejercitadas en la demanda: $1 .^{\circ}$ La exclusión en el Catálogo de las especies Batrachocytrium dendrobatidis, Udaria pinnatifida, Helianthus tuberosus, Cyprinus carpio, Oncorhynchus mykiss, debiendo consecuentemente quedar éstas incluidas en dicho Catálogo".

Es más, suponía el desdecir el carácter de un hecho, el ser especie invasora, confirmado por decenas de estudios científicos y al que no puede acogerse a la excepción para su suelta en el medio natural de la normativa europea de acuicultura y mucho menos si se pretende solo que sea la trucha común la que limite las sueltas de la trucha arcoíris, de la misma manera que se anuló la disposición relativa al visón americano respecto de las granjas en las zonas del visón europeo, pues los efectos de la trucha arcoíris van mucho más allá de que compitan dos especies próximas ${ }^{20}$. Al respecto de esta especie, el FJ 4 de la STS de 2016 merece ser reproducido en sus puntos más importantes ${ }^{21}$.

\footnotetext{
${ }^{19}$ Recomendamos la lectura, con abundante información científica y de la situación española de este documento: RÍOS CON VIDA, Truchas invasoras: Informe sobre la ilegalidad de las sueltas masivas de trucha arcoíris (Oncorhynchus mykiss) y variedades alóctonas de trucha común (Salmo trutta) con fines de pesca deportiva, Madrid, 2010.

${ }^{20}$ El recurso a la reductio ad absurdum y el mero sentido común nos lleva a la misma conclusión ilógica si lo comparásemos con la hipotética suelta de pumas u otros felinos alóctonos en toda España menos en las zonas en las que habita el lince ibérico. Aunque a lo mejor no es tan hipotética: Siete detenidos en Badajoz por participar en un safari ilegal en el que se mató un tigre, El Mundo de 7 de diciembre de 2005.

21 "5.- Oncorhynchus mykiss: Nombre común o vulgar: Trucha Arco Iris.

Se trata de otro pez acerca de cuya naturaleza exótica e invasora se ha pronunciado el perito judicial con toda nitidez, sobre la base de la declaración general inicial de su informe, válida para la especie anterior: "...el perito informa que la carpa (Cyprinus carpio) y la trucha arco-iris (Oncorhynchus mykiss) son especies exóticas invasoras con un elevado potencial de afección al medio ambiente receptor tal y como lo demuestra la abundante bibliografía relativa a los efectos de estas dos especies y que se exponen a continuación...". A partir de la manifestación, de indudable peso en nuestro enjuiciamiento, de que la trucha arco iris está también incluida entre las 100 especies invasoras más peligrosas a nivel mundial por la IUCN, el perito, apoyado en numerosa bibliografía, describe los impactos bajo estas rúbricas: Introducción de enfermedades; Hibridación; Piscivoría; Competencia con otras especies de peces; Eliminación de anfibios; Reducción/eliminación de comunidades de macroinvertebrados por prelación; Efectos sobre las aves; y alteraciones del comportamiento de otros salmónidos.
} 
En cualquier caso, le certeza científica queda a extramuros de la potestad legislativa ${ }^{22} \mathrm{y}$ reglamentaria, pues los hechos o se dan o no se dan, pero no pueden ser a tales efectos objeto de una votación, máxime yendo contra una sentencia firme, ni, como hemos visto, puede quedar en el margen de discrecionalidad administrativa. Tal como afirmó en su día el maestro de juristas D. Eduardo $G^{\text {a }}$ de Enterría $^{23}$ :

"No puede quedar al arbitrio de la Administración discernir si un hecho se ha cumplido o no se ha cumplido, o determinar que algo ha ocurrido si realmente no ha sido así. El milagro, podemos decir, no tiene cabida en el campo del Derecho Administrativo".

Y tal potestad milagrera, reiteramos, le es ajena a todo cuerpo legislativo, so pena de incurrir en la inconstitucionalidad de la norma por violación de los fundamentos básicos del Estado de Derecho y a su vez so pena de incurrir en una ridícula falta de responsabilidad que las Cortes Generales no podrían cometer en modo alguno, como nos recuerdan algunos rocambolescos antecedentes históricos en Derecho comparado por cuya similitud el caso actual se nos presenta como imposible ${ }^{24}$.

\footnotetext{
Tales conclusiones no son controvertidas, en modo alguno, desde el único punto de vista jurídico que importa para la resolución de este litigio, que es el relativo a la caracterización de la trucha arco iris como especie exótica invasora, por razón de su negativa influencia en el medio ambiente y en la biodiversidad y, por ende, en su exigible adscripción al Catálogo Español de las Especies Exóticas Invasoras (...).
}

Por lo demás, el contenido de la disposición transitoria tercera del Real Decreto cuya impugnación estudiamos ahora, sobre "Sueltas con especies alóctonas no catalogadas objeto de aprovechamiento piscícola o cinegético", arranca del punto de partida de que estamos ante una especie alóctona no catalogada, lo que a la vista de lo que venimos exponiendo, constituye una base fáctica que no puede mantenerse, toda vez que la mencionada disposición se refiere exclusivamente a especies no afectadas por la prohibición del artículo 52.2 de la Ley 42/2007, de 13 de diciembre, según el cual: "2. Las Administraciones públicas competentes prohibirán la introducción de especies, subespecies o razas geográficas alóctonas cuando éstas sean susceptibles de competir con las especies silvestres autóctonas, alterar su pureza genética o los equilibrios ecológicos", prohibición que debe alcanzar, obviamente, a la trucha arco iris (...)".

${ }^{22}$ Otro ejemplo, a pesar de todo, lo tenemos en la reforma de la LPNB de 2015, por la cual se eliminaron las "razas geográficas alóctonas" del art. 52 de la LPNB de 2007, con el evidente fin de permitir las sueltas de ejemplares de trucha común centroeuropeas o de otras cuencas o partes de cuencas ibéricas, pese a los riesgos probados de introgresión genética. Ahora, el nuevo art. 54 de la LPNB dice así: " La Administración General del Estado prohibirá la importación o introducción de especies o subespecies alóctonas cuando éstas sean susceptibles de competir con las especies silvestres autóctonas, alterar su pureza genética o los equilibrios ecológicos". Vid. RÍOS CON VIDA,Truchas fuera de lo común. Los perjuicios ambientales provocados por las sueltas ilegales para la pesca fluvial de ejemplares alóctonos de trucha común, Madrid, 2013.

${ }^{23}$ GARCÍA DE ENTERRÍA, E. y FERNÁNDEZ RODRÍGUEZ, T.R., Curso de Derecho Administrativo, Madrid, Civitas, Madrid. $5^{\text {a }}$ ed. 1989 , p. 535 y ss.

${ }^{24}$ En efecto, como convertir el número pi en $3^{\prime} 2$ o aprobar también en sede parlamentaria la cuadratura del círculo, como sucedió en la Asamblea del Estado de Indiana. Vid: Cuando políticos de EE.UU. decidieron que el número pi era 3'2, El País, de 12 de febrero de 2017. 
VII. LA PROPOSICIÓN DE LEY INCLUÍA LA RENUNCIA ILEGAL A LAS COMPETENCIAS ADMINISTRATIVAS Y LA DESCONSIDERACIÓN DE LA VALIDEZ DE LA PRUEBA CIENTÍFICA

Este mismo art. 64 ter incluye una cuestión que vulnera el ejercicio irrenunciable de las competencias administrativas ${ }^{25}$ y la validez de la prueba científica:

"Artículo 64 ter. Especies catalogadas como exóticas invasoras introducidas en el medio natural con anterioridad a la entrada en vigor de la Ley 42/2007, de 13 de diciembre, objeto de aprovechamiento piscícola o cinegético. Sueltas con la especie trucha arco iris. 1. Para evitar que las especies catalogadas objeto de aprovechamiento piscícola o cinegético, introducidas en el medio natural antes de la entrada en vigor de la Ley 42/2007, de 13 de diciembre, se extiendan fuera de los límites de sus áreas de distribución anteriores a esa fecha, su gestión, control o posible erradicación se podrá realizar, en esas áreas, a través de la caza y la pesca, incluyendo todas sus modalidades, incluidas las reguladas por las Federaciones Deportivas Españolas de Caza y de Pesca, cuando este objetivo quede recogido en los instrumentos normativo de caza y pesca".

Sorprende dicha referencia a unos organismos privados en el ejercicio de una potestad exclusivamente pública. Las federaciones deportivas son entidades privadas que, solo en relación con las competiciones oficiales, podrán realizar por delegación funciones públicas $^{26}$. Es decir, su naturaleza jurídica es privada y solo ejercen, por delegación funciones públicas respecto de las competiciones oficiales y solo estas, en el ámbito estrictamente competitivo ya que las delegaciones son expresas, pero en la caza y pesca recreativas generales y en las cuestiones ambientales y de aguas, estas entidades

\footnotetext{
${ }^{25}$ Art. 8 de la Ley 40/2015, de 1 de octubre, del Sector Público: "1. La competencia es irrenunciable y se ejercerá por los órganos administrativos que la tengan atribuida como propia, salvo los casos de delegación o avocación, cuando se efectúen en los términos previstos en ésta u otras leyes". La irrenunciabilidad de las competencias es, como es conocido, un principio básico del Derecho Administrativo, por lo que huelga todo comentario posterior.

${ }^{26}$ Art. 30 de la Ley 10/1990, de 15 de octubre, del Deporte: "1. Las Federaciones deportivas españolas son Entidades privadas, con personalidad jurídica propia, cuyo ámbito de actuación se extiende al conjunto del territorio del Estado, en el desarrollo de las competencias que le son propias, integradas por Federaciones deportivas de ámbito autonómico, Clubes deportivos, deportistas, técnicos, jueces y árbitros, Ligas Profesionales, si las hubiese, y otros colectivos interesados que promueven, practican o contribuyen al desarrollo del deporte. 2. Las Federaciones deportivas españolas, además de sus propias atribuciones, ejercen, por delegación, funciones públicas de carácter administrativo, actuando en este caso como agentes colaboradores de la Administración pública".
} 
privadas carecen de toda potestad, y a la Administración le es imposible delegar estas funciones en ellas.

Dado que las especies y variedades alóctonas medran especialmente en los ecosistemas acuáticos, nos remitimos a la Directiva 2000/60/CE, Marco del Agua (DMA), cuyo fin para las aguas superficiales era la consecución del "buen estado ecológico" en el año 2015 (art. 4), lo que incluye, como es obvio, la calidad biológica y del que estamos muy lejos de cumplir, con las posibles sanciones para el Reino de España que han de tener siempre presente los responsables políticos del Ministerio de Agricultura y las Comunidades Autónomas.

A ello se suma el que, ciñéndonos al caso de la fauna íctica en ríos y humedales, a la hora de calificar una masa de aguas superficial como en "muy buen estado ecológico", "buen estado" o "estado aceptable" se exige por la DMA estudiar la "composición y abundancia de especies", lo que nos recuerda el caso generalizado de que en gran parte de nuestras cuencas las poblaciones autóctonas estén en franca regresión debido precisamente a la presencia de especies exóticas debido a la pesca recreativa, la acuicultura y la acuarofilia. La propia Comisión Europea ${ }^{27}$ reconoce las especies invasoras como una de las presiones a tener en cuenta en el proceso de la correcta transposición de la DMA y en relación con los espacios de la Red Natura 2000.

Acudiendo al argumento lógico de la comparación y la reductio ad absurdum, y con todos los respetos, no podrían las federaciones de automovilismo o de deportes aéreos intervenir y regular a su criterio aspectos de la seguridad vial o aérea, por lo que en el caso de la caza $^{28}$ y la pesca, sus federaciones deportivas no podrían suplir los propios métodos científicos y técnicos destinados a la generalidad de la gestión ambiental de ecosistemas, máxime en dominio público hidráulico ${ }^{29}$. Es el conocido recurso a la prohibida extensión del monopolio de funciones públicas a otros sectores que le son totalmente ajenos, que el Parlamento no puede dar por bueno, so pena de erosionar los principios básicos de las potestades públicas mediante la sustitución de la

\footnotetext{
${ }^{27}$ COMISIÓN EUROPEA, Guidance on aquaculture and Natura 2000.Sustainable aquaculture activities in the context of the Natura 2000 Network, Bruselas, 2012.

${ }^{28}$ Especialmente es importante la cuestión del arruí, cuyo carácter invasor en España no deja lugar a dudas, siendo anulada la exclusión de su carácter de invasora en la Región de Murcia

${ }^{29}$ ¿Qué haríamos entonces con los diversos órganos científicos y su función consultiva pública en caso de un inevitable conflicto, ya que la certeza científica sobre las especies invasoras es abrumadora?
} 
Administración por criterios de entidades privadas ${ }^{30}$, con consecuencias como la nulidad del acto administrativo por tener un contenido imposible y de la disposición reglamentaria por vulnerar normas de rango superior.

En cualquier caso, subyace una cuestión muy importante: Estas entidades privadas desplazarían de hecho los resultados y métodos científicos y técnicos que se decidiera aplicar para el control y erradicación de las especies invasoras, como los del Comité Científico del Comité de Fauna y Flora Silvestres del RD 1391/2011, de 4 de febrero, sobre la materia. La misma reductio ad absurdum nos llevaría a conclusiones inaceptables en casos como la medicina y farmacia, los controles de alcoholemia o la homologación de vehículos, por citar unos meros ejemplos.

\section{LA APLICACIÓN ERRÓNEA POR LA PROPOSICIÓN DE LEY DEL REGLAMENTO EUROPEO DE ESPECIES EXÓTICAS EN LA ACUICULTURA}

Por último, el art. 64 quáter de la PL decía:

«Artículo 64. Uso de las especies exóticas y las especies localmente ausentes en la acuicultura. La utilización de especies exóticas en la acuicultura, incluidas las catalogadas como especies exóticas invasoras, se regirá por lo dispuesto en el Reglamento 708/2007, del Consejo, de 11 de junio de 2007, sobre el uso de las especies exóticas y las especies localmente ausentes en la acuicultura.»

El recurso a este Reglamento de la UE supone una muestra del desconocimiento del Derecho de la UE y de la propia norma europea. Así es, este Reglamento evidentemente se impone a la legislación nacional, pero solo hace referencia a la acuicultura como medio de producción animal destinado al consumo y no a su suelta en el medio natural (art. 2 del Reglamento), siempre que la certeza científica lo permita.

Por tanto, esta confusión de los redactores de la PL no puede tener cabida y además, cuenta sin efecto alguno, dado que no es necesario que se publique esta remisión normativa al Reglamento de la UE, ejemplo una vez más de una pésima técnica legislativa, por duplicación de algo ya existente y por, quizás, pretender que la norma

\footnotetext{
30 BRUFAO CURIEL, P., La extensión del monopolio sobre funciones públicas de las federaciones deportivas a las actividades recreativas o de ocio, CEFLegal: Revista Práctica de Derecho. Comentarios y casos prácticos, núm. 165, 2014.
} 
europea permite la suelta en el medio natural de estas especies invasoras, a la vez que desconoce el principio de subsidiariedad, de prevención y de cautela en cuestiones ambientales.

Recordamos que siempre que se cumplan estos requisitos, la cría de ciertas especies se permite con fines comerciales en la UE.

\section{NOTA SOBRE LA NUEVA PROPOSICIÓN DE LEY PRESENTADA EN OCTUBRE DE 2017}

Se ha vuelto a presentar una proposición de ley de reforma de la LPNB el pasado 20 de octubre en el Congreso de los Diputados ${ }^{31}$. Es prácticamente idéntica a la anterior ya rechazada, incluso en su numeración, salvo en una mención por remisión a la legislación sectorial, agrícola, sanitaria, cinegética, forestal y de pesca. En esta normativa no existe, salvo algún detalle, el tratamiento de las especies invasoras, lo que en la práctica puede suponer evitar el análisis científico y debate previo ante la suspensión de la inclusión de una especie en el Catálogo Español de Especies Exóticas e Invasoras (CEEI) o su descatalogación. Como puede sospecharse, no hace ninguna referencia a la inclusión por motivos de esta legislación sectorial a la inclusión en el CEEI.

Este añadido del art. 64.2 propuesto dice en este añadido:

"En los supuestos con regulación específica, en especial en la legislación de montes, caza, agricultura, sanidad y salud pública pesca continental y pesca marítima, en casos excepcionales en los que concurran motivos imperiosos de interés público, incluidos los de naturaleza social o económica, la comisión estatal para el patrimonio natural y la biodiversidad podrá acordar, mediante decisión motivada y pública, la suspensión del procedimiento de catalogación de una especie o promover la descatalogación de una especie previamente catalogada".

Es precisamente el presentar otra iniciativa legislativa idéntica sin base jurídica científica y jurídica es más un pésimo ejemplo de técnica legislativa, ya que tampoco se puede conocer qué legislación aparte de aquella que cita, "en especial" dice,

\footnotetext{
${ }^{31}$ BOCG, Serie B, n 170-1, de 27 de octubre de 2017, pág.1. Precisamente, esta normativa sectorial es la relacionada con varias especies objeto de la sentencia: el arruí, las sueltas de trucha arcoíris al medio natural (no su explotación comercial como alimento), el visón americano, el cangrejo rojo, el alga wakame o la carpa.
} 
ambigüedad y falta de concreción por remisión que, en la práctica, puede suponer una generalización de la excepción del empleo económico de estas especies. Tengamos en cuenta asimismo que hay obligaciones derivadas del Derecho internacional y europeo que no pueden soslayarse por mor de una referencia a la normativa española sectorial vacía de contenido. La referencia a los motivos de "imperioso interés público" es, una vez, una equivocada alusión a los que con los mismos términos se establece en la Directiva de Hábitats, interpretada muy restrictivamente por el Tribunal Europeo ${ }^{32}$.

Ello significa que no solo la nueva proposición siga adoleciendo de la misma tacha constitucional, legal y científica de la proposición rechazada en junio de 2017 , sino que el régimen general de las especies invasoras se puede convertir en un "flatus vocis" o "hollow shibboleth", es decir, en una normativa cuyas excepciones la vacían de contenido real, ya que el origen y fin de estas proposiciones de ley presentadas en 2017 no es otro que evitar la aplicación y la obediencia, basada en el Estado de Derecho y en la lealtad institucional de una sentencia firme del Tribunal Supremo y sus efectos de cosa juzgada material, la "reserva de jurisdicción" y el derecho fundamental a la tutela judicial efectiva.

\section{CONCLUSIONES}

La PL adolecía de graves vicios de inconstitucionalidad por la vulneración de la tutela judicial efectiva, de los efectos de la cosa juzgada material, de la reserva de jurisdicción y de la separación de poderes, al dirigirse sin duda a evitar los efectos de una sentencia firme del Tribunal Supremo, cuya ratio decidendi y fallo es el objeto claro de la reforma que se pretendió aprobar, a la vez que se desdeñaban los criterios básicos de la técnica legislativa.

La reforma propuesta habría supuesto también la vulneración del principio de la irrenunciabilidad de las competencias administrativas y el ejercicio de funciones públicas que le está vetado a entidades privadas ajenas totalmente a la gestión ambiental y al mundo científico, criterios básicos del Derecho Público que han de respetarse.

Asimismo, la PL atentaba contra la objetividad de los poderes públicos exigible en cuestiones fácticas y científicas cuya certeza es indubitada, ajenas a cualquier posible

${ }^{32}$ GALlego BeRnARD, M ${ }^{\mathrm{a}}$ S., La Red Natura 2000 en España. Régimen jurídico y análisis jurisprudencial, Seo/Birdlife, Madrid, 2015. 
votación sobre el carácter invasor de determinadas especies y sus efectos ambientales, a la vez que vuelve a emplear erróneamente conceptos científicos para fines distintos como el de "recursos zoogenéticos", cuestión anulada por el Tribunal Supremo. Recordamos que el bien jurídico protegido es la biodiversidad autóctona silvestre y que las excepciones propuestas convierten esta proposición de ley, de hecho, en una ley de caso único.

Por todas estas razones de peso, la PL rechazada carecía del mínimo amparo legal y constitucional. Todas estas cuestiones las han de tener en cuenta los responsables administrativos y políticos ante una eventual, como así parece ser, vuelta a la reforma a la baja de la LPNB, ya que la nueva proposición no es sino una versión, aun más grave si cabe, de lo rechazado en junio de 2017.

\section{BIBLIOGRAFÍA}

BRUFAO CURIEL, P., El Derecho y la Ciencia, o cómo desdeñar la sentencia del Tribunal Supremo sobre el catálogo de especies protegidas y negar la certeza científica, Revista Aranzadi Doctrinal, núm. 4, 2017.

BRUFAO CURIEL, P., Normas de convalidación de actos y disposiciones administrativas anuladas en sede contenciosa, en Bauzá Martorell, F. J. (dir.): Derecho Administrativo y Derecho Penal: Reconstrucción de los límites, Bosch, Barcelona, 2017.

BRUFAO CURIEL, P., La extensión del monopolio sobre funciones públicas de las federaciones deportivas a las actividades recreativas o de ocio,CEFLegal: Revista Práctica de Derecho. Comentarios y casos prácticos, núm. 165, 2014.

BRUFAO CURIEL, P., Las especies exóticas y el Derecho, con especial referencia a las especies acuáticas, la pesca recreativa y la acuicultura, Revista Catalana de Derecho Ambiental, núm. 1, vol. 3, 2012.

COLlAZOS STÜWE, A., Comentarios al Decreto 213/2009, de 20 de noviembre, por el que se aprueban medidas para el control de especies invasoras en la Comunidad Valenciana, Revista Aranzadi de Derecho Ambiental, núm. 20, 2011.

COMISIÓN EUROPEA, Guidance on aquaculture and Natura 2000.Sustainable aquaculture activities in the context of the Natura 2000 Network, Bruselas, 2012. 
GALLEGO BERNARD, Ma S., La Red Natura 2000 en España. Régimen jurídico y análisis jurisprudencial, Seo/Birdlife, Madrid, 2015.

GARCÍA DE ENTERRÍA, E. y FERNÁNDEZ RODRÍGUEZ, T.R., Curso de Derecho Administrativo, Madrid, Civitas, Madrid. $5^{\text {a }}$ ed. 1989.

LOZANO CUTANDA, B., El Tribunal Supremo amplía el catálogo de especies invasoras (Sentencia de 16 de marzo de 2016), Actualidad Jurídica Ambiental, núm. 56, 2016.

RÍOS CON VIDA, Truchas fuera de lo común. Los perjuicios ambientales provocados por las sueltas ilegales para la pesca fluvial de ejemplares alóctonos de trucha común, Madrid, 2013.

RÍOS CON VIDA, Truchas invasoras: Informe sobre la ilegalidad de las sueltas masivas de trucha arcoíris (Oncorhynchus mykiss) y variedades alóctonas de trucha común (Salmo trutta) con fines de pesca deportiva, Madrid, 2010.

SORIANO GARCÍA, J. E. y BRUFAO CURIEL, P., Claves de Derecho Ambiental, Vol. II, Medio Natural biodiversidad y riesgos tecnológicos, Iustel, Madrid, 2011.

UNIÓN EUROPEA, Especies exóticas invasoras. La respuesta de la Unión Europea, Luxemburgo, 2014. 